\title{
Characterization of anti-BCG benz[a]anthraquinones and new siderophores from a Xinjiang desert-isolated rare actinomycete Nocardia sp. XJ31
}

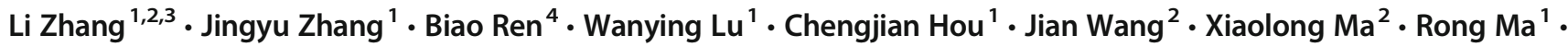 \\ Mei Liu ${ }^{2} \cdot$ Zhiheng Liu ${ }^{2} \cdot$ Jin-Ping $\mathrm{Li}^{5} \cdot$ Kan Ding $^{6,7} \cdot$ Huanqin Dai ${ }^{2} \cdot$ Lixin Zhang $^{1} \cdot$ Xueting Liu $^{1}$
}

Received: 2 July 2020 / Revised: 5 August 2020 / Accepted: 14 August 2020 / Published online: 24 August 2020

(C) Springer-Verlag GmbH Germany, part of Springer Nature 2020

\begin{abstract}
The current global demand for novel anti-TB drugs has drawn urgent attention on the discovery of natural product compounds with anti-TB activity. Lots of efforts have emphasized on environmental samples from unexplored or underexplored natural habits and identified numerous rare actinomycete taxa producing structurally diverse bioactive natural products. Herein, we report a survey of the rare actinobacteria diversity in Xinjiang region together with the discovery of anti-TB active natural products from these strains. We have collected 17 soil samples at different sites with different environmental conditions, from which 39 rare actinobacteria were identified by using a selective isolation strategy with 5 media variations. Among those isolated strains, XJ31 was identified as a new Nocardia sp. based on 16S rRNA gene analysis. Through one strain-many compounds (OSMAC) strategy combined with anti-Bacillus Calmette-Guérin bioassay-guided isolation, two groups of compounds were identified. They were twelve siderophores (nocardimicins, 1-12) and two anthraquinones (brasiliquinones, 13 and 14) and ten of them were identified as new compounds. The structures of the purified compounds were elucidated using HR-ESI-MS, 1D NMR, and 2D NMR techniques. The anti-TB bioassays revealed that the two benz $[\alpha]$ anthraquinones have potent activity against BCG (MICs $=25 \mu \mathrm{M})$, which can be used as a promising start point for further anti-TB drug development.
\end{abstract}

\section{Key points}

- Ten new natural products were identified from Nocardia sp. XJ31.

- Brasiliquinones 13 and 14 showed moderate anti-BCG activity.

Keywords Xinjiang desert $\cdot$ Nocardia $\mathrm{sp}$. Anti-BCG $\cdot$ Brasiliquinone $\cdot$ Nocardimicin

Li Zhang and Jingyu Zhang contributed equally to this work.

Electronic supplementary material The online version of this article (https://doi.org/10.1007/s00253-020-10842-2) contains supplementary material, which is available to authorized users.

Huanqin Dai

daihq@im.ac.cn; daihuanqin@139.com

$\triangle$ Xueting Liu

liuxueting@ecust.edu.cn

1 State Key Laboratory of Bioreactor Engineering, East China University of Science and Technology, Shanghai 200237, China

2 The State Key Laboratory of Mycology (SKLM), Institute of Microbiology, Chinese Academy of Sciences, Beijing 100101, China

3 Department of Chemistry, Boston University, Boston, MA 02215, USA
4 State Key Laboratory of Oral Diseases \& National Clinical Research Center for Oral Diseases, West China Hospital of Stomatology, Sichuan University, Chengdu 610041, China

5 Department of Medical Biochemistry and Microbiology, SciLifeLab Uppsala, The Biomedical Center, University of Uppsala, Husargatan 3, 75123 Uppsala, Sweden

6 Glycochemistry \& Glycobiology Lab, Key Laboratory of Receptor Research, Shanghai Institute of Materia Medica, Chinese Academy of Sciences, Shanghai 201203, China

7 University of Chinese Academy of Sciences, No. 19(A) Yuquan Road, Beijing 100049, China 


\section{Introduction}

Tuberculosis (TB) is a chronic infectious disease caused by Mycobacterium tuberculosis and is one of the top 10 global causes of death caused by a single infectious agent. According to a WHO report, TB caused 1.3 million deaths in 2018, and 10.0 million people are estimated to have developed TB in 2017. More than $90 \%$ of the infection cases occur in developing countries such as India (27\%), China (9\%), and Indonesia (8\%) (WHO 2018). In addition, the high incidence of HIV/TB co-infection, together with the emergence of multi-drugresistant $M$. tuberculosis strains, is now believed to pose a huge threat to global human health (Mesfin et al. 2014). Currently, anti-TB treatment is largely limited to drugs which were developed decades ago like ethionamide (1960), ethambutol (1961), capreomycin (1963), and rifampicin (1963) (Liu et al. 2016). Despite the recent approval of two new drugs, bedaquiline (2012) (Andries et al. 2005) and delamanid (2014) (Matsumoto et al. 2006), there is still a rising need for novel anti-TB drugs due to the fact that acquired resistance has been observed in therapy process (Bloemberg et al. 2015). Anti-TB drug discovery has not kept pace with increasing levels of drug resistance (Dheda et al. 2017) and efforts are being made to discover such compounds.

Natural products (NPs) are small molecules evolutionary selected by nature (in some sense pre-validated for bioactivity) that often display unique chemical diversity (Cragg and Newman 2013; Liu et al. 2012; Newman and Cragg 2016). Seven out of 11 currently used nature-derived TB drugs were either isolated from microbes or semi-synthesized from microbial natural products (Liu et al. 2016), and almost 60\% of the antibiotics that are currently used in clinic for TB treatment are produced by Streptomyces (Ashforth et al. 2010). Driven by substantial overlap in the structures of newly discovered antiTB compounds from Streptomyces, researchers have begun to focus on rare actinobacteria, which are viewed as vast potential reservoirs of novel NPs (Dhakal et al. 2017). Microbes from extreme environments such as deep-sea sediments and hot springs harbor unique secondary metabolite biosynthesis genes and possess high potentials of chemical space (Jiang et al. 2014; Okoro et al. 2009; Pettit 2011). Microorganisms from extreme environments have received extensive research attention because they can yield basic biological insights via comparisons of more widespread physiological processes versus the unique physiological mechanisms that allow them to exist and even thrive in extreme conditions (Meklat et al. 2011). These microorganisms are known to produce many structurally diverse NPs (Katz and Baltz 2016).

In the course of our previous screening work seeking for anti-TB NPs from microorganisms, we have developed a screening assay that tests the compound's growth inhibitory activity against Bacillus Calmette-Guérin (BCG), which is an attenuated strain of the bovine tuberculosis bacillus $M$. bovis (Ashforth et al. 2010; Huang et al. 2016; Liu et al. 2014a; Wang et al. 2013). Here, we examined the biodiversity of rare actinobacteria sampled from extreme environments in the Xinjiang region and investigated their anti-BCG natural products. Seventeen samples were collected from different sites from diverse ecological systems in Xinjiang, resulting in isolation of 260 actinomycete strains. Phylogeny analysis of 40 strains with distinct morphological features indicated the presence of strains from 8 genera, highlighting the biodiversity of the rare actinobacteria present in these locations. Strain XJ31 of the Nocardia genus was examined in detail and a systematic natural product profiling and isolation program led to the purification and structural elucidation of 14 compounds from XJ31 based on HR-ESI-MS, 1D NMR, and 2D NMR techniques. Twelve of these compounds are oligopeptides (siderophores), including nocardimicin B (1), nocardimicin $\mathrm{D}(\mathbf{2})$, nocardimicin $\mathrm{F}(\mathbf{3})$, and nocardimicins J-R (4-12), while the remaining two are the benz $[\alpha]$ anthraquinones brasiliquinones D (13) and E (14). Notably, 10 out of the 14 compounds described in this study have not been reported previously (4-12 and 14), and the two benz $[\alpha]$ anthraquinones showed good activity against BCG $(\mathrm{MICs}=25 \mu \mathrm{M})$ in bioassays.

\section{Materials and methods}

\section{General experimental procedures}

NMR spectra were obtained on a Bruker Avance DRX500 spectrometer (Bruker, Billerica, USA). Chemical shifts were calibrated internally against residual solvent signals (Pyridine$d_{5}: \delta_{\mathrm{C}} 123.87 / 135.91 / 150.35, \delta_{\mathrm{H}} 7.22 / 7.58 / 8.74 ; \mathrm{CD}_{3} \mathrm{OD}: \delta_{\mathrm{C}}$ 49.0, $\left.\delta_{\mathrm{H}} 3.31 / 4.87\right)$. HR-ESI-MS analysis was conducted on a Bruker micrOTOF mass spectrometer. Resin HP-20 (Diaion, Osaki, Japan), Sephadex LH-20 (GE Healthcare BioSciences AB, Marlborough, USA), and ODS-A (YMC, Wesel, Germany) were used for isolation. HPLC analysis was performed using an Agilent 1100 Series HPLC; data analysis was conducted using ChemStation Rev.B.02.01 software.

\section{Isolation of rare actinobacteria by selective isolation methods}

The actinomycete-selective isolation media (Table S1) used in the present study comprised HV agar (Hayakawa and Nonomura 1987), SM3 agar (Tan et al. 2006), MOPS agar, Starch-Casein-Nitrate agar (Küster and Williams 1964), and AV (arginine vitamins) agar (Nonomura 1969). Soil samples were pretreated at $80{ }^{\circ} \mathrm{C}$ for $1 \mathrm{~h}$. One gram of soil sample collected from different locations was then suspended in 10 $\mathrm{mL}$ of sterile water individually. After vortexing, the 
supernatant was spread onto isolation media and grown for 7 -14 days at $28^{\circ} \mathrm{C}$. Visible colonies were then transferred onto ISP2 agar (Shirling and Gottlieb 1966) for purification and long-term storage.

\section{Microbial strain culture and identification}

Strain XJ31 was isolated from a soil sample collected from Xinjiang, China, in July 2011, and maintained on ISP2 agar (4\% glucose, $10 \%$ malt extract, $4 \%$ yeast extract, $2 \%$ agar, $\mathrm{pH}$ 7.0) at $28^{\circ} \mathrm{C}$. The identification of strain XJ31 was performed based on both morphological and 16S rDNA phylogenetic analysis. Mature aerial mycelium and substrate mycelium pigmentation were recorded on ISP2 agar media after incubation at $28{ }^{\circ} \mathrm{C}$ for 7 days. Genomic DNA extractions were carried out following a standard CTAB procedure as described in Practical Streptomyces Genetics (Kieser et al. 2000). A pair of primers (27F: 5'-GAGAGTTTGATCCTGGCTCAG-3'; 1492R: 5'-CTACGGCTACCTTGTTACGA-3') was used to amplify the $16 \mathrm{~S}$ rDNA. PCR $(25 \mu \mathrm{L}$ volume in total: contains $2.5 \mu \mathrm{L} 10 \times$ buffer (Takara), $2 \mu \mathrm{L} 2.5 \mathrm{nM}$ dNTP (Takara), 0.5 $\mu \mathrm{L}$ of each $20 \mu \mathrm{M}$ primer, $1.5 \mathrm{U}$ rTaq polymerase (Takara), and $1 \mu \mathrm{L}$ DNA template) was performed on a Takara PCR Thermal Cycler with the initial denaturation at $95{ }^{\circ} \mathrm{C}$ for 5 min, followed by 28 cycles of denaturation $\left(95^{\circ} \mathrm{C}, 30 \mathrm{sec}\right)$, annealing $\left(55^{\circ} \mathrm{C}, 30 \mathrm{sec}\right)$ and elongation $\left(72^{\circ} \mathrm{C}, 1 \mathrm{~min} 30 \mathrm{~s}\right)$, and a final elongation at $72{ }^{\circ} \mathrm{C}$ for $10 \mathrm{~min}$. Multiple sequence alignment of $16 \mathrm{~S}$ rRNA gene with the related species was carried out using ClustalW (Thompson et al. 1994). A phylogenetic tree was constructed using the neighbor-joining method (Saitou and Nei 1987) by MEGA 7.0 (Tamura et al. 2011). Bootstrap values were calculated by resampling 1000 replicates (Felsenstein 1985).

Strain XJ31 has been deposited at the China General Microbiological Culture Collection Center (accession number 4.7298). The nucleotide sequences of the 16S rRNA gene have been deposited with NCBI (accession number KT951165).

\section{Fermentation, extraction, and isolation}

Twenty-one different actinomycete fermentation media (Table S2) were used for the small-scale fermentation of strain $\mathrm{XJ} 31$. Prior to fermentation, strain XJ31 was cultivated on an ISP2 agar plate at $28^{\circ} \mathrm{C}$ for 5 days. Each $250-\mathrm{mL}$ Erlenmeyer flask containing $40 \mathrm{~mL}$ of fermentation broth $(5 \%$ of inoculum) was inoculated with a small portion $\left(1 \mathrm{~cm}^{2}\right)$ of mycelium on agar and grew for 7 days at $28^{\circ} \mathrm{C}$ with shaking at $220 \mathrm{rpm}$. The fermentation broth was then extracted using $40 \mathrm{~mL}$ of a water/EtOAc (v/v: 1:1) solvent system, and the crude extracts were analyzed by HPLC-UV analysis with an Eclipse XDB$\mathrm{C} 8,5 \mu \mathrm{m}$ column $(4.6 \times 150 \mathrm{~mm}$, Agilent $)$ using a gradient elution: $5-99 \% \mathrm{ACN} / \mathrm{H}_{2} \mathrm{O}$ for $30 \mathrm{~min}, 99 \% \mathrm{ACN}$ for $10 \mathrm{~min}$.
Large-scale fermentation was performed using a two-step seed culture process. The primary seed culture used a $250-\mathrm{mL}$ Erlenmeyer flask containing $40 \mathrm{~mL}$ of ISP2 medium which was inoculated with mycelium of XJ31 grown on ISP2 agar and incubated at $28^{\circ} \mathrm{C}$, at $220 \mathrm{rpm}$ for 5 days. Aliquots (12 $\mathrm{mL}$ ) of the primary seed culture were used to inoculate four 1L Erlenmeyer flasks, each containing $250 \mathrm{~mL}$ of ISP2 broth to serve as a secondary seed culture. After incubation at $28{ }^{\circ} \mathrm{C}$, $220 \mathrm{rpm}$ for 5 days, aliquots $(15 \mathrm{~mL})$ of the secondary seed cultures were aseptically transferred into 801 -L Erlenmeyer flasks each containing $250 \mathrm{~mL}$ of Noc05 fermentation medium (starch $1.0 \%$, glucose $1.0 \%$, glycerol $1.0 \%$, corn steep $0.25 \%$, peptone $0.5 \%$, yeast extract $0.2 \%, \mathrm{NaNO}_{3} 0.1 \%$, $\mathrm{CaCO}_{3} 0.3 \%, \mathrm{pH}$ natural), and fermentation was carried out at $28{ }^{\circ} \mathrm{C}, 220 \mathrm{rpm}$ for 7 days. Fermentation broth was combined and centrifuged at $8000 \mathrm{rpm}$ for $10 \mathrm{~min}$ to separate supernatant and mycelia cake. Supernatant was extracted three times with $20 \mathrm{~L}$ of the aforementioned water/EtOAc solvent system and the organic layer was combined and concentrated by rotary evaporation. The crude extract was initially fractionated using an ODS-MPLC $(35 \times 2.2 \mathrm{~cm})$ using a stepwise gradient of $5-100 \% \mathrm{MeOH} / \mathrm{H}_{2} \mathrm{O}$ for $70 \mathrm{~min}$ and $100 \%$ $\mathrm{MeOH}$ for $40 \mathrm{~min}$, yielding five fractions (fraction 1 5).

Fraction 5 was dried by rotary evaporation yielding $90 \mathrm{mg}$ crude extract, which was then fractionated on a Sephadex LH20 column $(50 \times 3 \mathrm{~cm})$ in $\mathrm{MeOH}$ yielding six subfractions (fraction 5-1 5-6). Fraction 5-3 (5 mg) was further purified by reverse phase HPLC (ZORBAX RX-C8 $9.4 \times 250 \mathrm{~mm}, 5 \mu \mathrm{m}$ column, $2.5 \mathrm{~mL} / \mathrm{min}$, gradient elution: $45 \% \mathrm{ACN} / \mathrm{H}_{2} \mathrm{O}$ for $30 \mathrm{~min}$ and $99 \% \mathrm{ACN}$ for $10 \mathrm{~min})$ yielding $\mathbf{1 3}\left(t_{\mathrm{R}}=19.11\right.$ $\min ; 1.0 \mathrm{mg})$ and $\mathbf{1 4}\left(t_{\mathrm{R}}=28.38 \mathrm{~min} ; 2.5 \mathrm{mg}\right)$.

The mycelia cake was extracted three times with $1 \mathrm{~L}$ acetone and the organic layer was combined and concentrated by rotary evaporation. The crude extract $(2.3 \mathrm{~g})$ was passed through an ODS-MPLC $(35 \times 2.2 \mathrm{~cm})$ developed by a stepwise gradient of $70-90 \% \mathrm{MeOH} / \mathrm{H}_{2} \mathrm{O}$ for $45 \mathrm{~min}, 90-100 \%$ $\mathrm{MeOH}$ for $30 \mathrm{~min}, 100 \% \mathrm{MeOH}$ for $45 \mathrm{~min}, 100-90 \%$ $\mathrm{MeOH} / \mathrm{CH}_{2} \mathrm{Cl}_{2}$ for $30 \mathrm{~min}, 90-80 \% \mathrm{MeOH} / \mathrm{CH}_{2} \mathrm{Cl}_{2}$ for 20 $\min , 80 \% \mathrm{MeOH} / \mathrm{CH}_{2} \mathrm{Cl}_{2}$ for $40 \mathrm{~min}$, and $100 \%$ isopropanol for 50 min yielding seven fractions (fraction 6 12). LC-MS analysis and UV absorption characteristics revealed that fraction 8 contained a series of siderophore-type compounds. However, the purification was challenged due to the peak overlapping on HPLC as well as the different ion-chelating forms of siderophores. Thus, chelation with $\mathrm{GaBr}_{3}$ of fraction 8 solution was applied in order to stabilize all compounds in their $\mathrm{Ga}^{3+}$ chelation form for feasible purification. Fraction 8 $(1.2 \mathrm{~g})$ was dissolved in $400 \mathrm{~mL} \mathrm{MeOH}$ and mixed with $2.5 \mathrm{~g}$ $\mathrm{GaBr}_{3}$ (dissolved in $6 \mathrm{~mL} \mathrm{MeOH}$ ) at room temperature for $1 \mathrm{~h}$ to yield fraction $8 \mathrm{a}$. Fraction $8 \mathrm{a}$ was then fractionated by ODS-MPLC $(35 \times 2.2 \mathrm{~cm})$ developed by a stepwise gradient of $85-100 \% \mathrm{MeOH} / \mathrm{H}_{2} \mathrm{O}$ for $60 \mathrm{~min}, 100 \% \mathrm{MeOH}$ for 30 min, $100-90 \% \mathrm{MeOH} / \mathrm{CH}_{2} \mathrm{Cl}_{2}$ for $30 \mathrm{~min}, 90-80 \%$ 
$\mathrm{MeOH} / \mathrm{CH}_{2} \mathrm{Cl}_{2}$ for $20 \mathrm{~min}$, and $100 \%$ isopropanol for $30 \mathrm{~min}$ to yield subfractions (fractions $8 \mathrm{a}-1 \sim 8 \mathrm{a}-7$ ). Fraction $8 \mathrm{a}-3$ (126 $\mathrm{mg}$ ) was further fractionated on reverse phase HPLC (ZORBAX RX-C $89.4 \times 250 \mathrm{~mm}, 5 \mu \mathrm{m}$ column, $2.5 \mathrm{~mL} /$ min, isocratic elution with $68 \% \mathrm{ACN} / \mathrm{H}_{2} \mathrm{O}$ for $52 \mathrm{~min}$ ) to give 1a $\left(t_{\mathrm{R}}=19.1 \mathrm{~min} ; 13.7 \mathrm{mg}\right), \mathbf{4 a}\left(t_{\mathrm{R}}=23.2 \mathrm{~min} ; 8.7 \mathrm{mg}\right)$, and 5a $\left(t_{\mathrm{R}}=28.4 \mathrm{~min} ; 13.7 \mathrm{mg}\right)$. Fraction $8 \mathrm{a}-4(83.5 \mathrm{mg})$ was fractionated on reverse phase HPLC (ZORBAX RX-C 9.4 $\times 250 \mathrm{~mm}, 5 \mu \mathrm{m}$ column, $2.5 \mathrm{~mL} / \mathrm{min}$, isocratic elution with $63 \% \mathrm{ACN} / \mathrm{H}_{2} \mathrm{O}$ for $\left.52 \mathrm{~min}\right)$ to give $2 \mathrm{a}\left(t_{\mathrm{R}}=35.8 \mathrm{~min} ; 10.5\right.$ $\mathrm{mg}), \mathbf{6 a}\left(t_{\mathrm{R}}=40.0 \mathrm{~min} ; 5.5 \mathrm{mg}\right)$, and $7 \mathbf{a}\left(t_{\mathrm{R}}=51.0 \mathrm{~min} ; 4.7\right.$ $\mathrm{mg})$. Fraction $8 \mathrm{a}-5(173 \mathrm{mg})$ was fractionated on reverse phase HPLC (ZORBAX RX-C $39.4 \times 250 \mathrm{~mm}, 5 \mu \mathrm{m}$ column, $2.5 \mathrm{~mL} / \mathrm{min}$, eluted with $70 \% \mathrm{ACN} / \mathrm{H}_{2} \mathrm{O}$ for $36 \mathrm{~min}$ and 70 $-90 \% \mathrm{ACN} / \mathrm{H}_{2} \mathrm{O}$ for $\left.9 \mathrm{~min}\right)$ to give $\mathbf{3 a}\left(t_{\mathrm{R}}=25.4 \mathrm{~min} ; 14.0\right.$ $\mathrm{mg}), 8 \mathrm{a}\left(t_{\mathrm{R}}=30.5 \mathrm{~min} ; 9.0 \mathrm{mg}\right)$, and $9 \mathrm{a}\left(t_{\mathrm{R}}=36.1 \mathrm{~min} ; 5.7\right.$ $\mathrm{mg})$. Fraction $8 \mathrm{a}-6(300 \mathrm{mg})$ was first passed through a Sephadex LH-20 column developed by $\mathrm{MeOH}$ to yield four fractions (fraction 8a-6-1 8a-6-4). Fraction 8a-6-3 which contained the siderophores was further fractionated by reverse phase HPLC (ZORBAX RX-C $89.4 \times 250 \mathrm{~mm}, 5 \mu \mathrm{m}$ column, $2.5 \mathrm{~mL} / \mathrm{min}$, isocratic elution with $63 \% \mathrm{ACN} / \mathrm{H}_{2} \mathrm{O}$ for $52 \mathrm{~min}$ ) to obtain $10 \mathrm{a}\left(t_{\mathrm{R}}=31.2 \mathrm{~min} ; 3.0 \mathrm{mg}\right), 11 \mathrm{a}\left(t_{\mathrm{R}}=35.9 \mathrm{~min} ; 2.8\right.$ $\mathrm{mg})$, and 12a $\left(t_{\mathrm{R}}=41.6 \mathrm{~min} ; 1.8 \mathrm{mg}\right)$.

\section{Anti-BCG bioassay}

The anti-BCG bioactivity of isolated compounds was tested following the previously described procedure (Wang et al. 2013; Wayne 2002). The assay was performed with a strain of Mycobacterium bovis (BCG Pasteur 1173P2) containing a constitutive green fluorescent protein (GFP) expression vector (pUV3583c-GFP) using direct readout of fluorescence as a measure of bacterial growth, as described previously (Wang et al. 2010a, b). The BCG strain was pre-cultivated to mid-log phase (7 days) at $37{ }^{\circ} \mathrm{C}$ in Middlebrook $7 \mathrm{H} 9$ broth $(40 \mathrm{~mL}$; Difco) supplemented with $10 \%$ OADC enrichment (Becton Dickinson), $0.05 \%$ Tween-80, and $0.2 \%$ glycerol and then diluted to an OD600 of 0.025 with broth. A twofold serial dilution of each compound to be tested (4000 to $31.3 \mu \mathrm{g} / \mathrm{mL}$ in DMSO) was prepared and an aliquot of each dilution $(2 \mu \mathrm{L})$ was added to a 96-well flat-bottom microtiter plate (Greiner). Isoniazid was used as the positive control and DMSO as the negative control. An aliquot (78 $\mu \mathrm{L})$ of the BCG-GFP bacterial suspension was then added to each well (to give final compound concentrations of 100 to $0.78 \mu \mathrm{g} / \mathrm{mL}$ in $2.5 \%$ DMSO) and the plate was incubated at $37{ }^{\circ} \mathrm{C}$ for 3 days. Mycobacterial growth was determined by measuring GFPfluorescence using an EnVision 2103 Multilabel Plate Reader (Perkin-Elmer Life Sciences) with excitation at $485 \mathrm{~nm}$ and emission at $535 \mathrm{~nm}$. All the experiments were performed in triplicate. MIC was defined as the minimum concentration that inhibited more than $90 \%$ of bacteria growth.

\section{Results}

\section{Isolation of rare actinomycete by selective isolation methods}

We have isolated more than 600 actinobacterial strains from soil samples collected from 17 sampling sites in Xinjiang region (Fig. 1A and Table S3) using the five selective isolation media. All strains were de-replicated based on phenotype and morphology, and 260 actinobacteria strains were selected to build the culture library (data not shown). These actinobacteria strains isolated from Xinjiang environment exhibited a high degree of phenotypic diversity (Fig. 1B) and many of them showed distinct phenotypes from Streptomyces. The presence of these rare actinobacteria emphasizes the unique microbial diversity characteristic of the Xinjiang area and supports the idea of extreme diverse environment being an important resource for new chemical compounds. The phylogeny of these taxa was further investigated based on $16 \mathrm{~S}$ rRNA gene sequence analysis: the 40 strains with distinct morphologies were subjected to systematic taxonomy analysis and were found to belong to 8 genera, including Micromonospora, Nocardia, Modestobacter, Glycomyces, Prauserella, Haloactinopolyspora, Plantactinospora, Polyangium, and Acinetobacter (Fig. 1B and Fig. S15). This diversified phylogeny composition underscores that the Actinobacteria of Xinjiang have great potential as a potential source of novel natural products. Among these 260 actinobacteria strains, strain XJ31 was identified as a new Nocardia species according to 16S rRNA phylogenetic analysis. Moreover, the HPLC profile of XJ31 exhibits high compound diversity and abundance; thus, strain XJ31 was chosen for detailed characterization.

\section{Characterization of strain XJ31 and structural elucidation and biological activities evaluation of its natural product compounds}

After incubation at $28{ }^{\circ} \mathrm{C}$ for 7 days, strain XJ31 formed a puce-colored colony on ISP2 plates (Fig. 1C). No diffusible pigments were produced. Phylogenetic analysis of the strain's 16S rRNA gene sequence (Fig. 2) demonstrated that strain XJ31 belongs to the genus Nocardia, exhibiting closest similarity to the $16 \mathrm{~S}$ rRNA gene sequence of $N$. sungurluensis (97.94\%) (Camas et al. 2014).

HPLC analysis of crude extracts from XJ13 fermentation broth supernatant revealed an apparently diverse profile of natural product compounds (Fig. 3A). Using the fractionation scheme detailed in the "Materials and methods" section, 
(a)

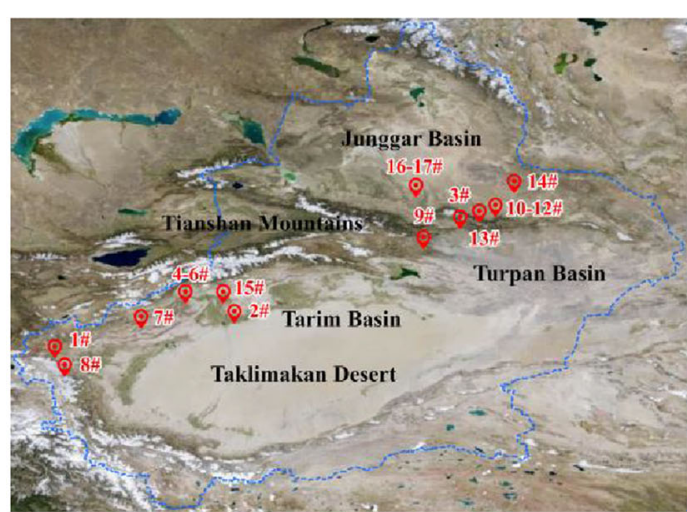

(b)

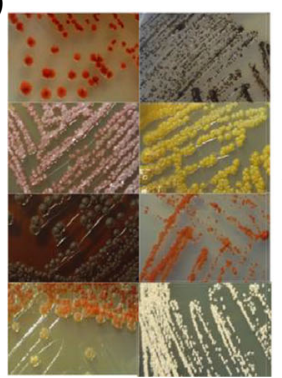

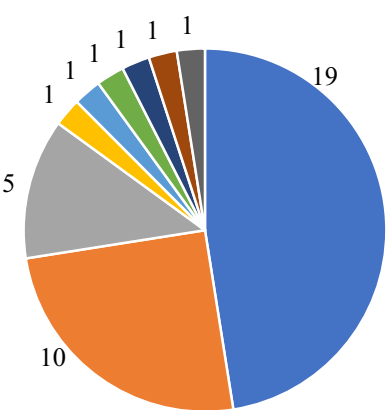

Fig. 1 A survey of rare actinobacteria and anti-BCG compounds from Xinjiang region. (A) The sampling sites in Xinjiang region (Table S3). (B) Colony characteristics and overview of the rare actinomycete genera

multiple compounds were purified, and subsequent anti-BCG bioassay-guided isolation led to the isolation of two benz $[\alpha]$ anthraquinones, brasiliquinones $\mathrm{D}(\mathbf{1 3})$ and $\mathrm{E}(\mathbf{1 4})$ (Fig. 3B). Furthermore, siderophores detected in fraction 8 were chelated with $\mathrm{Ga}^{3+}$ prior to purification. The iron complex of siderophores is typically stable and easy for separation; however, the ferric iron present in ferric siderophore exists in a paramagnetic high spin $\mathrm{d}^{5}$ state which causes severe line broadening of the NMR signals. Thus, $\mathrm{Ga}^{3+}$ or the $\mathrm{Al}^{3+}$ siderophore complexes are usually employed for NMR experiments (Jalal and van der Helm 1991). A 10-fold excess of $\mathrm{GaBr}_{3}$ was added into fraction 8 and clearly separated peaks were apparent in HPLC analyses of siderophore-containing

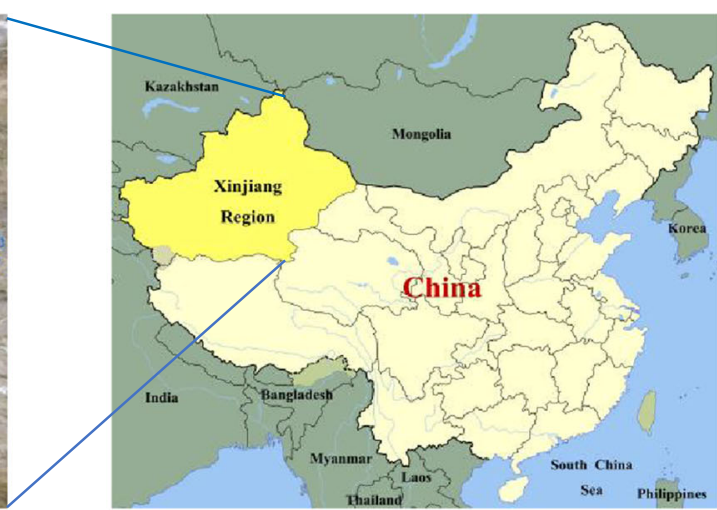

- Micromonospora

- Nocardia

- Modestobacter

Glycomyces

- Prauserella

- Haloactinopolyspora

- Plantactinospora

- Polyangium

- Acinetobacter

(c)

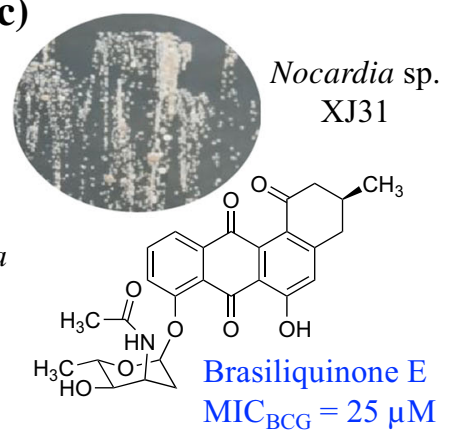

(assessed using 16S rRNA gene sequences) based on selected isolation of microbes. (C) Colony characteristics of the XJ31 strain, and the isolated anti-TB active compound brasiliquinone $\mathrm{E}$

fractions (Fig. 4A). Meanwhile, a metal-to-ligand charge transfer band at $\lambda_{\max }=340 \mathrm{~nm}$ (Seyedsayamdost et al. 2011) was observed (Fig. 4C), compared with the band at $\lambda_{\max }=308 \mathrm{~nm}$ for $\mathrm{Ga}^{3+}$ free-siderophores (Fig. 4B). After chelation with $\mathrm{GaBr}_{3}$, twelve Ga-siderophores complexes (1a-12a) were subsequently purified and used for acquisition of NMR spectra, which allowed the structural elucidation of nocardimicins B, D, F, and J R (1-12) (Fig. 3B). Among these identified siderophores, $\mathbf{4 - 1 2}$ and $\mathbf{1 4}$ are previously unreported structures.

Compound 4a was isolated as a white powder. The molecular formula was deduced as $\mathrm{C}_{40} \mathrm{H}_{58} \mathrm{~N}_{5} \mathrm{O}_{10} \mathrm{Ga}$ based on HRESI-MS data (Fig. S4a) $\left(\mathrm{m} / z 838.3530[\mathrm{M}+\mathrm{H}]^{+}\right.$, calcd. for
Fig. 2 Neighbor-joining phylogenetic tree based on $16 \mathrm{~S}$ rRNA gene sequences from $\mathrm{XJ} 31$ and related species constructed using MEGA 7.0, with Rhodococcus rhodochrous DSM $43241^{\mathrm{T}}$ as the outgroup. Numbers at nodes indicate levels of bootstrap support (\%) based on a neighbor-joining analysis of 1000 resampled datasets. NCBI accession numbers are given. Bar, 0.01 nucleotide substitutions per site

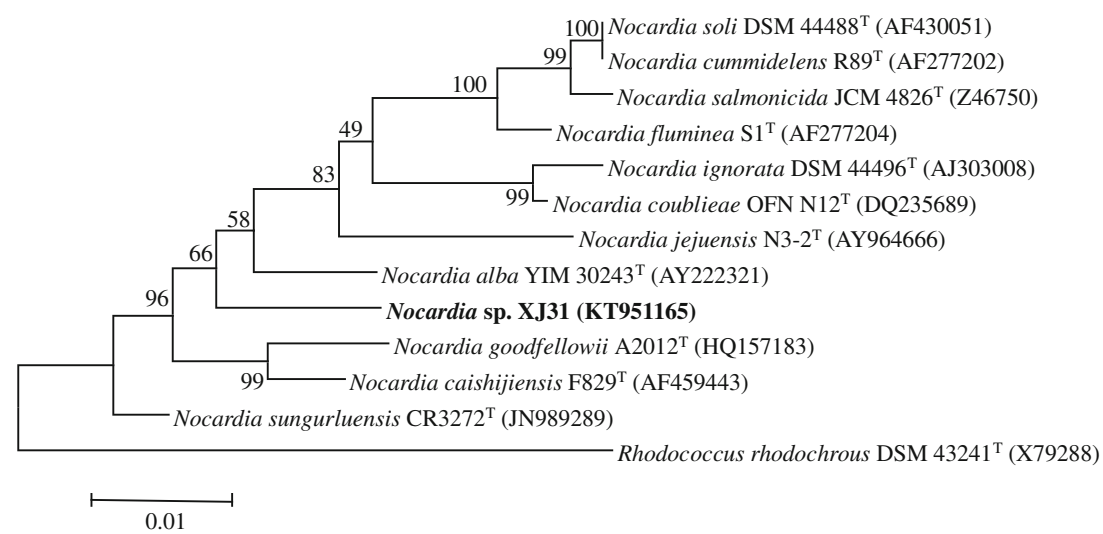


(a)

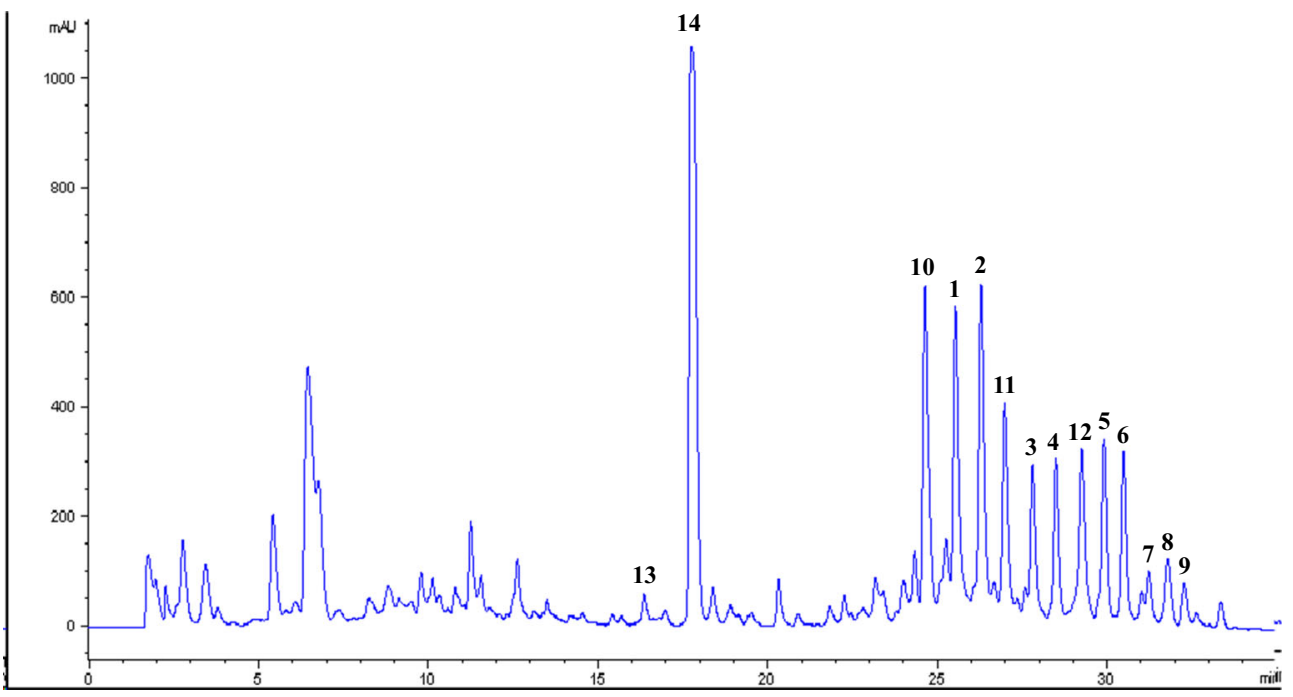

(b)

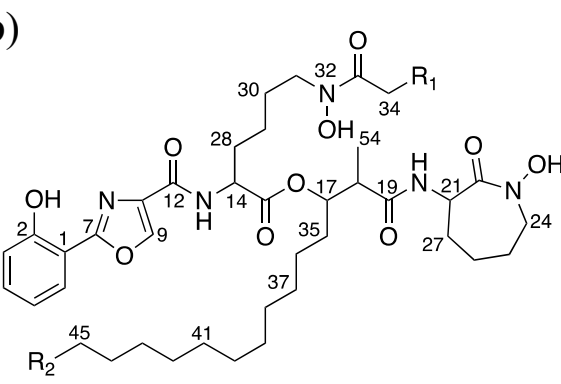

\section{Nocardimicins}

B (1) $\mathrm{R}_{1}=\mathrm{H}, \mathrm{R}_{2}=\mathrm{H}$

D (2) $\mathrm{R}_{1}=\mathrm{H}, \mathrm{R}_{2}=\mathrm{C}_{2} \mathrm{H}_{5}$

F (3) $\mathrm{R}_{1}=\mathrm{H}, \mathrm{R}_{2}=\mathrm{C}_{4} \mathrm{H}_{9}$

J (4) $\mathrm{R}_{1}=\mathrm{CH}_{3}, \mathrm{R}_{2}=\mathrm{H}$

$\mathrm{K}$ (5) $\mathrm{R}_{1}=\mathrm{C}_{2} \mathrm{H}_{5}, \mathrm{R}_{2}=\mathrm{H}$

$\mathrm{L}$ (6) $\mathrm{R}_{1}=\mathrm{CH}_{3}, \mathrm{R}_{2}=\mathrm{C}_{2} \mathrm{H}_{5}$

$\mathrm{M}$ (7) $\mathrm{R}_{1}=\mathrm{C}_{2} \mathrm{H}_{5}, \mathrm{R}_{2}=\mathrm{C}_{2} \mathrm{H}_{5}$

$\mathrm{N}(\mathbf{8}) \mathrm{R}_{1}=\mathrm{CH}_{3}, \mathrm{R}_{2}=\mathrm{C}_{4} \mathrm{H}_{9}$

$\mathrm{O}$ (9) $\mathrm{R}_{1}=\mathrm{C}_{2} \mathrm{H}_{5}, \mathrm{R}_{2}=\mathrm{C}_{4} \mathrm{H}_{9}$

$\mathrm{P}$ (10) $\mathrm{R}_{1}=\mathrm{H}, \mathrm{R}_{2}=\mathrm{C}_{6} \mathrm{H}_{13}$

$\mathrm{Q}$ (11) $\mathrm{R}_{1}=\mathrm{CH}_{3}, \mathrm{R}_{2}=\mathrm{C}_{6} \mathrm{H}_{13}$

$\mathrm{R}$ (12) $\mathrm{R}_{1}=\mathrm{C}_{2} \mathrm{H}_{5}, \mathrm{R}_{2}=\mathrm{C}_{6} \mathrm{H}_{13}$

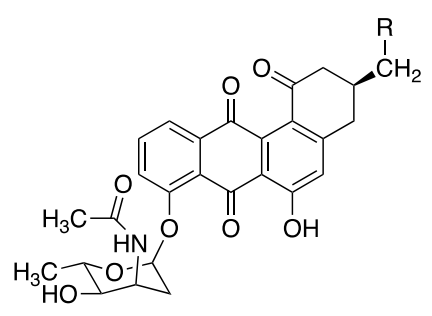

Brasiliquinone D (13) $\mathrm{R}=\mathrm{CH}_{3}$

Brasiliquinone $\mathrm{E}(\mathbf{1 4}) \mathrm{R}=\mathrm{H}$

Fig. 3 HPLC-UV profiles of crude extracts of strain XJ31 cultured in medium (A). Noc05 and structures of isolated compounds (1-14) (B)

(a)
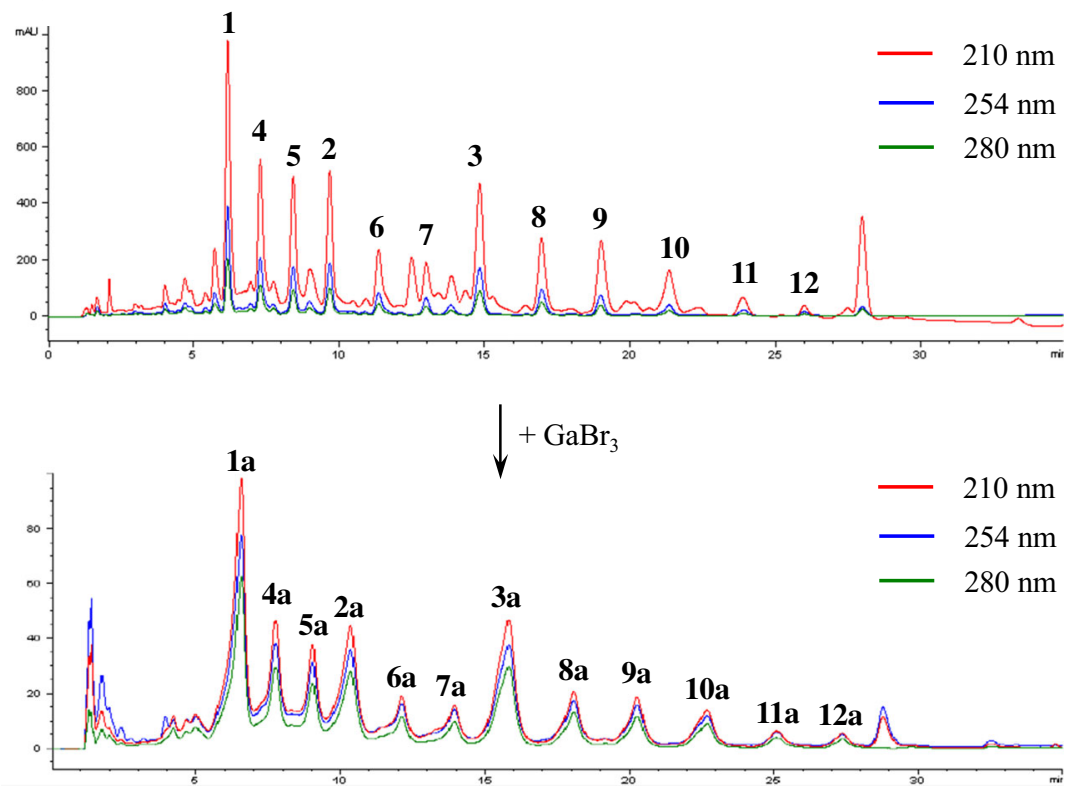

(b)

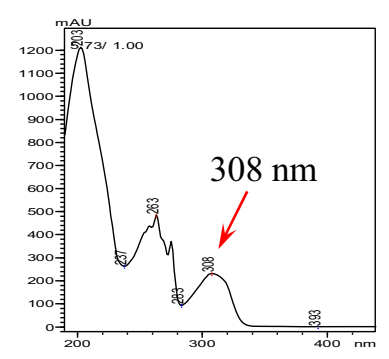

(c)

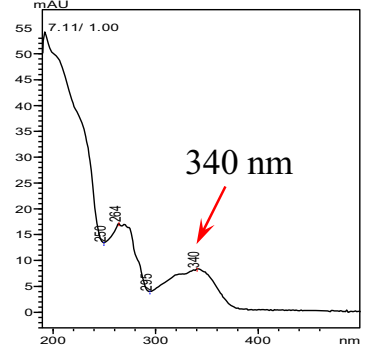

Fig. 4 HPLC profiles of siderophores-containing fraction (upper panel of A) and chelation with $\mathrm{GaBr}_{3}$ (lower panel of A). UV spectra of siderophores (B) and their $\mathrm{Ga}^{3+}$ complexes (C) 
838.3512 ) with 13 degrees of unsaturation. Combined analysis of ${ }^{1} \mathrm{H}$ NMR, ${ }^{13} \mathrm{C}$ NMR, and HSQC spectra (Figs. S4bS4d) of $4 \mathbf{a}$ indicated the presence of two amide protons $\left(\delta_{\mathrm{H}}\right.$ 10.11 and 7.94), a 1,2-disubstituted benzene moiety $\left(\delta_{\mathrm{C}} / \delta_{\mathrm{H}}\right.$ $167.6,135.4 / 7.39,128.1 / 8.01,123.4 / 7.30,117.0 / 6.79$, and $112.5)$, three methyl groups $\left(\delta_{\mathrm{C}} / \delta_{\mathrm{H}} 17.2 / 1.35,14.8 / 0.88\right.$, and $10.1 / 1.03)$, five carbonyl carbons $\left(\delta_{\mathrm{C}} 172.2,171.9,166.8\right.$, 163.9 , and 159.9), three additional aromatic carbons $\left(\delta_{\mathrm{C}}\right.$ $166.3,143.2$, and 136.4$)$, one oxymethine $\left(\delta_{\mathrm{C}} / \delta_{\mathrm{H}} 78.1 / 5.36\right)$, two nitrogen-bearing methylenes $\left(\delta_{\mathrm{C}} / \delta_{\mathrm{H}} 53.5 / 3.45\right.$ and $49.3 /$ $4.00)$, two nitrogen-bearing methine $\left(\delta_{\mathrm{C}} / \delta_{\mathrm{H}} 55.7 / 4.83\right.$ and 45.8/2.95), 17 methylenes, and one methine (Table S4). These data revealed that $\mathbf{4 a}$ had a nocardimicin-type framework, by comparison with those of previously reported compounds (Ikeda et al. 2005).

The ${ }^{1} \mathrm{H}-{ }^{1} \mathrm{H}$ COSY and HMBC experiments (Figs. S4e and S4f) of 4a revealed four sub-structures A D shown in Fig. 5: a hydroxyphenyloxazoline, a fatty acid moiety, and two lysinederived moieties. The sub-structure A was determined by HMBC correlations from $\mathrm{H}-3$ to $\mathrm{C}-1$ and $\mathrm{C}-5$, from $\mathrm{H}-6$ to C-2, C-4, and C-7, and from H-9 to C-7, C-10, and C-12. The proton spin systems of sub-structure $\mathrm{B}$ could be determined by COSY correlations of H-13/H-14, H-14/H-28b, H-28/H-29, $\mathrm{H}-29 \mathrm{a} / \mathrm{H}-30 \mathrm{~b}$, and H-30/H-31 and correlation of H-34/H-52 . HMBC correlations from $\varepsilon$-methylene proton $\mathrm{H}-31$ and a triplet methyl proton $\mathrm{H}-52$ to $\mathrm{C}-33$ indicated the presence of a propanoyl group at $\mathrm{N}-32$. The sub-structure $\mathrm{B}$ was thus determined as $N_{\varepsilon}$-propanoyllysine. Sub-structure $\mathrm{C}$ was elucidated as 2-methyl-3-hydroxytetradecanoid acid according to the COSY correlations shown in blue color, together with HMBC correlations from $\mathrm{H}-17$ and H-54 to C-19. Substructure $\mathrm{D}$ was deduced from HMBC correlations of $\mathrm{H}-21$ / C-22, H-20/C-22, and H-24/C-22.

The organization of the sub-structures was determined based on HMBC experiments (Fig. S4f). The relationship of sub-structures A and B was confirmed by HMBC correlation from $\mathrm{H}-13$ to $\mathrm{C}-12$. The connectivity of sub-structures $\mathrm{B}$ and $\mathrm{C}$ was established by the HMBC correlation of $\mathrm{H}-17 / \mathrm{C}-15$ through an ester bond. The HMBC correlations from $\mathrm{H}-20$ and $\mathrm{H}-21$ to C-19 indicated the linkage of the sub-structures
$\mathrm{C}$ and $\mathrm{D}$ through an amide bond. Based on molecular formula of $\mathbf{4 a}$, the remaining two hydroxyl groups were assigned as substituents at the nitrogen atoms N-23 and N-32. All of the signals in the 2D NMR spectra were assigned unambiguously (Table S4). These data supported the structure assigned to nocardimicin J (4) (Fig. 3), the $\mathrm{Ga}^{3+}$ free form of $4 \mathbf{a}$.

The molecular formulae of $\mathrm{Ga}^{3+}$-chelated nocardimicins $\mathrm{L}$ (6a), N (8a), and Q (11a) were deduced as $\mathrm{C}_{42} \mathrm{H}_{62} \mathrm{~N}_{5} \mathrm{O}_{10} \mathrm{Ga}$, $\mathrm{C}_{44} \mathrm{H}_{66} \mathrm{~N}_{5} \mathrm{O}_{10} \mathrm{Ga}$, and $\mathrm{C}_{46} \mathrm{H}_{70} \mathrm{~N}_{5} \mathrm{O}_{10} \mathrm{Ga}$, respectively, according to their HR-ESI-MS $\left([\mathrm{M}+\mathrm{H}]^{+} \mathrm{m} / z\right.$ 866.3836, 894.4152, and 922.4458) (Figs. S6a, S8a, and S11a). ${ }^{1} \mathrm{H}$ and ${ }^{13} \mathrm{C}$ NMR data of these compounds (Figs. S6b, S6c, S8b, S8c, S11b, and $\mathrm{S} 11 \mathrm{c})$ were very similar to those of $\mathbf{4 a}$. The ion mass of $\mathbf{6 a}$ was 28 mass units $\left(\mathrm{C}_{2} \mathrm{H}_{4}\right)$ larger than that of $4 \mathbf{a}$; the mass of $8 \mathbf{a}$ was 56 mass units $\left(\mathrm{C}_{4} \mathrm{H}_{8}\right)$ larger than $\mathbf{4 a}$, and that of $\mathbf{1 1 a}$ was 84 mass units $\left(\mathrm{C}_{6} \mathrm{H}_{12}\right)$ larger than $4 \mathbf{a}$. These data indicated that these compounds were the analogs of $\mathbf{4 a}$ differing in their fatty acid chain lengths. All of the signals in the 2D NMR spectra of these compounds were assigned unambiguously (Figs. S6dS6f, S8d-S8f, and S11d-S11f; Tables S6, S8, and S11). Based on these data, the structures of the $\mathrm{Ga}^{3+}$ free form of 6a, 8a, and 11a were determined as nocardimicins L (6), N (8), and Q (11) (Fig. 3).

Compound 5a was isolated as a white powder. The molecular formula was determined to be $\mathrm{C}_{41} \mathrm{H}_{60} \mathrm{~N}_{5} \mathrm{O}_{10}$ Ga based on HR-ESI-MS (Fig. S5a) $\left(\mathrm{m} / \mathrm{z} 852.3677[\mathrm{M}+\mathrm{H}]^{+}\right.$, calcd. for 852.3669) with 13 degrees of unsaturation. ${ }^{1} \mathrm{H}$ and ${ }^{13} \mathrm{C}$ NMR data (Figs. S5b and S5c) of $\mathbf{5 a}$ were very similar to those of 4a, except the presence of an extra methylene group $\left(\delta_{\mathrm{C}} / \delta_{\mathrm{H}}\right.$ 19.4/1.66-1.56). The COSY (Fig. S5d) correlations of H-34/ $\mathrm{H}-52$ and $\mathrm{H}-52 / \mathrm{H}-53$ revealed the existence of propyl group. The HMBC (Fig. S5f) correlations of H-34/C-33, H-34/C-52, $\mathrm{H}-52 / \mathrm{C}-33, \mathrm{H}-52 / \mathrm{C}-53$, H-53/C-34, and H-53/C-52 indicated the attachment of a butanoyl group at $\mathrm{N}-32$ of the lysine unit. Thus, the structure of the $\mathrm{Ga}^{3+}$ free form of $\mathbf{5 a}$ was analyzed via 2D NMR spectra (Figs. S5d-S5f; Table S5), and it was determined to be nocardimicin K (5) (Fig. 3). The ${ }^{1} \mathrm{H}$ and ${ }^{13} \mathrm{C}$ NMR data for 7a, 9a, and 12a (Figs. S7b, S7c, S9b, S9c, S12b, and S12c) were very similar to those of 5a: their HRESI-MS spectra indicated that these compounds are analogs of
Fig. 5 Key COSY and HMBC correlations for compounds 4 and 14

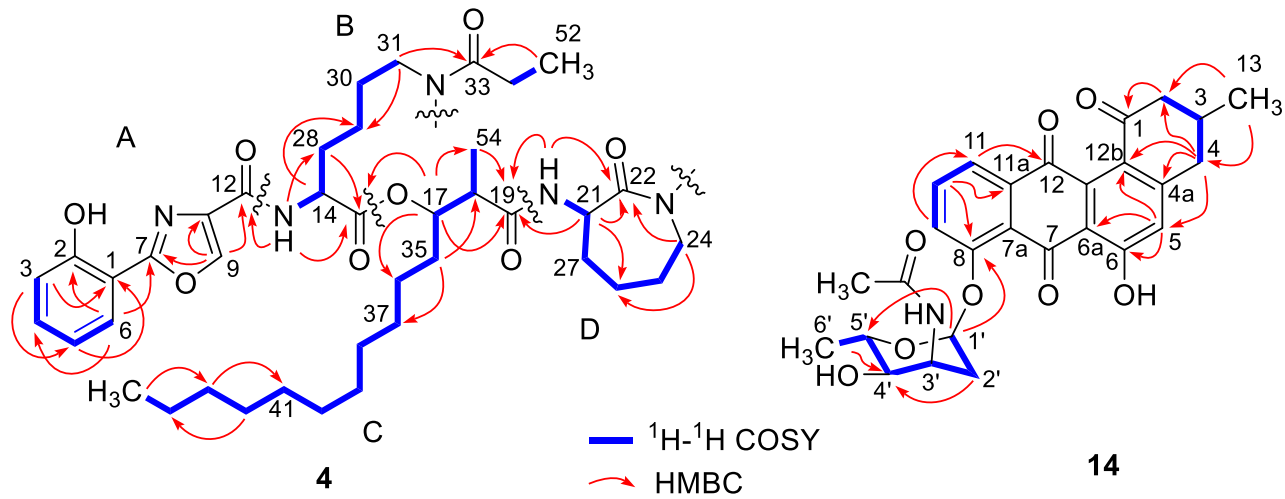


5a differing in their fatty acid chain lengths. The molecular formulae of $7 \mathbf{a}, 9 \mathbf{a}$, and $12 \mathbf{a}$ were determined to be $\mathrm{C}_{43} \mathrm{H}_{64} \mathrm{~N}_{5} \mathrm{O}_{10} \mathrm{Ga}, \mathrm{C}_{45} \mathrm{H}_{68} \mathrm{~N}_{5} \mathrm{O}_{10} \mathrm{Ga}$, and $\mathrm{C}_{47} \mathrm{H}_{72} \mathrm{~N}_{5} \mathrm{O}_{10} \mathrm{Ga}$, respectively, according to their HR-ESI-MS data ([M + $\mathrm{H}^{+} \mathrm{m} / z$ 880.3991, 908.4299, and 936.4622) (Figs. S7a, S9a, and S12a). The ion mass of $7 \mathbf{a}$ was 28 mass units $\left(\mathrm{C}_{2} \mathrm{H}_{4}\right)$ larger than that of $\mathbf{5 a}$, that of $\mathbf{9 a}$ was 56 mass units $\left(\mathrm{C}_{4} \mathrm{H}_{8}\right)$ larger, and that of $\mathbf{1 2 a}$ was 84 mass units $\left(\mathrm{C}_{6} \mathrm{H}_{12}\right)$ larger. All of the signals in 2D NMR spectra of these compounds were assigned unambiguously (Figs. S7d-S7f, S9d-S9f, and S12d-S12f; Tables S7, S9, and S12). Based on these data, the structures of the $\mathrm{Ga}^{3+}$ free forms of 7a, $9 \mathbf{a}$, and 12a were determined as nocardimicins $\mathrm{M}(\mathbf{7}), \mathrm{O}(\mathbf{9})$, and R (12) (Fig. 3).

Compound 10a was isolated as a white powder. The molecular formula was determined to be $\mathrm{C}_{45} \mathrm{H}_{68} \mathrm{~N}_{5} \mathrm{O}_{10} \mathrm{Ga}$ based on HR-ESI-MS (Fig. S10a) $\left(\mathrm{m} / z, 908.4301[\mathrm{M}+\mathrm{H}]^{+}\right.$, calcd. for 908.4295) with 13 degrees of unsaturation. ${ }^{1} \mathrm{H}$ and ${ }^{13} \mathrm{C}$ NMR data of 10a (Figs. S10b and S10c) were very similar to those of 11a, except for the absence of a methylene group. The HMBC (Fig. S10f) correlation between the methyl group $\mathrm{CH}_{3}-34\left(\delta_{\mathrm{C}} / \delta_{\mathrm{H}} 16.8 / 2.03\right)$ and the carbonyl group (C-33) indicated attachment of an acetyl group at N-32 of the lysine unit. Thus, the structure of the $\mathrm{Ga}^{3+}$ free form of 10a was determined to be nocardimicin P (10) (Figs. 3, S10d, and S10e; Table S10).

The structures of the three known siderophores, nocardimicin B (1), nocardimicin D (2), nocardimicin F (3), were determined based on the HR-ESI-MS, ${ }^{1} \mathrm{H}$ NMR, and ${ }^{13} \mathrm{C}$ NMR data of their $\mathrm{Ga}^{3+}$-chelated products 1a, 2a, and 3a (Figs. S1-S3), respectively, and by comparison with those of previous reports (Ikeda et al. 2005).

Compound 13 was obtained as a yellow amorphous powder. The molecular formula of $\mathbf{1 3}$ was established as $\mathrm{C}_{28} \mathrm{H}_{29} \mathrm{NO}_{8}$ on the basis of its HR-ESI-MS data $(\mathrm{m} / \mathrm{z}$ $508.1978[\mathrm{M}+\mathrm{H}]^{+}$, calcd. for 508.1966) (Fig. S13a). Compound 13 was determined to be brasiliquinone $\mathrm{D}$ according to combined analysis of its UV, ${ }^{1} \mathrm{H} N M R$, and ${ }^{13} \mathrm{C}$ NMR spectra (Figs. S13b-S13d; Table S13) and via comparison with previously reported data (Tsuda et al. 1999).

Compound 14 was obtained as a yellow amorphous powder and its molecular formula of $\mathbf{1 4}$ was deduced as $\mathrm{C}_{27} \mathrm{H}_{27} \mathrm{NO}_{8}$ on the basis of HR-ESI-MS data $(\mathrm{m} / \mathrm{z}$ $494.1828[\mathrm{M}+\mathrm{H}]^{+}$, calcd. for 494.1809) (Fig. S14a). The UV spectrum of $\mathbf{1 4}$ (Fig. S14b) was identical to that of 13, a finding indicating that these compounds both share the same benz $[\alpha]$ anthraquinone skeleton. The molecular mass of $\mathbf{1 4}$ was $\mathbf{1 4}$ mass units smaller than that of 13, indicating a difference of one $\mathrm{CH}_{2}$ in their structures. The ${ }^{1} \mathrm{H}$ and ${ }^{13} \mathrm{C}$ NMR data (Figs. S14c and S14d) of $\mathbf{1 4}$ were similar to those of $\mathbf{1 3}$, except the absence of a $\mathrm{CH}_{2}$ group $\left(\delta_{\mathrm{C}} / \delta_{\mathrm{H}} 29.0 / 1.53\right)$. The structure of 14 was analyzed via 2D NMR (Figs. 5 and S14e-S14g; Tables 1 and S14) and was determined to be the previously unreported compound brasiliquinone $\mathrm{E}$.

The anti-BCG activity of the isolated compounds was evaluated, and the two benz[ $\alpha]$ anthraquinones 13 and 14 both showed potent activity against BCG, with MIC values of around $25 \mu \mathrm{M}$.

\section{Discussion}

From the late 1940 s to 1960 s, many new antibiotics were isolated from actinobacteria during the Golden Age of antibiotic discovery. Approximately $60 \%$ of these antibiotics were discovered from the genus Streptomyces (Bérdy 2012). More recently, there has been extensive overlap in the reported compounds isolated from Streptomyces species, a situation which

Table 1 NMR data (500 MHz for ${ }^{1} \mathrm{H}$ NMR and $125 \mathrm{MHz}$ for ${ }^{13} \mathrm{C}$ $\mathrm{NMR}, \mathrm{CD}_{3} \mathrm{OD}$ ) for Brasiliquinone $\mathrm{E}$ (14)

\begin{tabular}{|c|c|c|c|c|}
\hline Pos. & $\delta_{\mathrm{C}}$ & $\delta_{\mathrm{H}}$, mult $(J$ in $\mathrm{Hz})$ & COSY & HMBC \\
\hline 1 & 200.3 & & & \\
\hline \multirow[t]{2}{*}{2} & 49.1 & $2.83, \mathrm{dd}(15.5,4.7)$ & $2 b, 3$ & 1 \\
\hline & & $2.53, \mathrm{~m}$ & 3 & $1,3,13$ \\
\hline 3 & 31.9 & $2.38, \mathrm{~m}$ & & \\
\hline \multirow[t]{2}{*}{4} & 39.2 & 3.02, dd $(16.7,3.9)$ & $3,4 b$ & $4 a, 12 b$ \\
\hline & & $2.7, \mathrm{dd}(16.7,10.6)$ & 3 & $2,3,4 a, 5,12 b, 13$ \\
\hline $4 a$ & 154.6 & & & \\
\hline 5 & 122.1 & $7.08, \mathrm{~s}$ & & $4,6,6 a, 12 b$ \\
\hline 6 & 164.8 & & & \\
\hline $6 a$ & 119.0 & & & \\
\hline 7 & 190.2 & & & \\
\hline $7 \mathrm{a}$ & 122.1 & & & \\
\hline 8 & 158.4 & & & \\
\hline 9 & 121.7 & $7.75, \mathrm{~d}(9.0)$ & 10 & 11 \\
\hline 10 & 137.8 & $7.83, \mathrm{t}(8.0)$ & 9,11 & $8,11 \mathrm{a}$ \\
\hline 11 & 121.2 & 7.73, d (7.7) & 10 & 8,12 \\
\hline $11 \mathrm{a}$ & 138.8 & & & \\
\hline 12 & 185.6 & & & \\
\hline $12 \mathrm{a}$ & 139.0 & & & \\
\hline $12 b$ & 129.3 & & & \\
\hline 13 & 21.6 & $1.18, \mathrm{~d}(6.6)$ & & $2,3,4$ \\
\hline $1^{\prime}$ & 96.8 & 5.97, d (3.2) & $2^{\prime} \mathrm{a}$ & $3^{\prime}, 5^{\prime}$ \\
\hline \multirow[t]{2}{*}{$2^{\prime}$} & 34.4 & $2.35, \mathrm{~m}$ & $2^{\prime} \mathrm{b}$ & \\
\hline & & $2.22, \mathrm{dd}(15.0,1.4)$ & & $1^{\prime}, 3^{\prime}, 4^{\prime}$ \\
\hline $3^{\prime}$ & 47.4 & $4.65, \mathrm{~m}$ & $2^{\prime} \mathrm{a}, 4^{\prime}$ & \\
\hline $4^{\prime}$ & 73.7 & 3.52 , dd $(10.0,4.3)$ & & $5^{\prime}, 6^{\prime}$ \\
\hline $5^{\prime}$ & 66.9 & $3.83, \mathrm{~m}$ & $4^{\prime}, 6^{\prime}$ & \\
\hline $6^{\prime}$ & 18.1 & $1.19, \mathrm{~d}(6.2)$ & & $4^{\prime}, 5^{\prime}$ \\
\hline $3^{\prime}-\mathrm{NAc}$ & 174.5 & & & \\
\hline $3^{\prime}$-NAc & 23.4 & $2.25, \mathrm{~s}$ & & $3^{\prime}-\mathrm{NAc}$ \\
\hline
\end{tabular}


has guided research attention away from this taxon and towards non-Streptomyces actinobacteria, which are sometimes referred to as "rare actinobacteria" (Subramani and Aalbersberg 2013; Subramani and Sipkema 2019). Unexplored (and underexplored) ecological environments are promising sources for the discovery of rare actinobacteria, and these organisms are believed to be rich sources for structurally diverse, yet unknown, compounds (Dhakal et al. 2017).

Xinjiang area harbors lots of highly diversified ecological environments, including salt lakes, deserts, and plateaus with saline-alkali soils. Our previous efforts to isolate rare actinobacteria from extreme environments such as work in the South China Sea and a Xinjiang desert have successfully described a series of new species from genera including Verrucosispora and Prauserella (Dai et al. 2010; Liu et al. 2014b; Wang et al. 2010a, b). In the present study, we continued a survey of the biological diversity of actinobacteria from the Xinjiang region and explored the potential anti-TB activity of NPs present in previously unknown strains. Using a selective isolation method, 40 rare actinobacteria belonging to eight genera were isolated from 17 samples collected in Xinjiang region. Among these rare genera, Micromonospora and Nocardia were dominant, representing $49 \%$ and $26 \%$ of the strains, respectively.

Further phylogenetic analysis based on 16S rRNA gene sequences emphasized the rarity of an actinomycete strain which we deemed Nocardia sp. XJ31 and that showed the highest similarity to $N$. goodfellowii $(97.81 \%)$. The natural product profile of XJ31 was evaluated using an OSMAC approach. Two classes of NPs, siderophores (1-12) and anthraquinones (13 and 14), were thusly identified from strain XJ31 fermentation extracts, including ten new compounds (nocardimicins $\mathrm{J}-\mathrm{R}$ and brasiliquinone $\mathrm{E}$ ).

According to earlier reports, nearly $40 \%$ of antimycobacterial compounds have been isolated from genera including Amycolatopsis, Nocardia, Actinomadura, Bacillus, Pleurotus, and Saccharopolyspora, all of which are similar to Mycobacterium strains (Ashforth et al. 2010; Butler and Buss 2006). Mukai et al. (2009) reported that a novel thiopeptide nocardithiocin, isolated from the pathogenic N. pseudobrasiliensis strain IFM 0757, was highly active against rifampicin-resistant as well as rifampicin-sensitive TB strains, exhibiting a range of MIC values from 0.025 to $1.56 \mu \mathrm{g} / \mathrm{mL}$. Our findings in the present study revealed that two anthraquinones, brasiliquinones D (13) and E (14), showed moderate anti-BCG activity $(\mathrm{MIC}=25 \mu \mathrm{M})$. Brasiliquinones were originally discovered from Nocardia brasiliensis by Tsuda et al. (1996). Brasiliquinone A-C exhibited anti-bacterial activity against $M$. smegmatis, in agreement with anti-BCG activity of brasiliquinone $\mathrm{E}$ in this study. The inspiration of looking for novel natural products with anti-TB activity was driven by the fact that the multi-drug resistance tuberculosis (MDR-TB) is rising with the current treatment such as isoniazid $(\mathrm{MIC}=1.4 \mu \mathrm{M})$ and rifampin $(\mathrm{MIC}=0.3 \mu \mathrm{M})($ Lee and Heifets 1987). Although brasiliquinones do not have comparable activity as indicated by MIC level, they still represent potential application value considering the drug resistance issue.

Nocardimicins A-F were discovered from Nocardia sp. TP-A0674 in the screening for muscarinic M3 receptorbinding inhibitors (Ikeda et al. 2005); thus, they are identified as potential candidates for neurotransmission disorder treatment. There has no reported anti-bacterial activity with nocardimicins, neither nocardimicins A-J exhibited inhibitory activity on BCG, MRSA, S. aureus, and B. subtilis (data not shown) analyzed with our inhouse bioassay. Besides, it is well known that iron is one of the major limiting factors and essential nutrients of microbial life (Litwin and Calderwood 1993). The nocardimicins represent the bulk of the NPs produced in Nocardia sp. XJ31; thus, the high yield could be the bacteria's response to the environment stress.

In nature, microorganisms produce small, high-affinity chelating molecules referred to as siderophores to facilitate their acquisition of iron (Saha et al. 2013). There are three types of siderophores, i.e., hydroxamates, catecholates, and carboxylates (Ali and Vidhale 2013). These molecules have been widely used in agricultural (Chaiharn et al. 2008), environmental (Ruggiero et al. 2000), and biomedical applications. In agriculture, siderophores have been used as biocontrol agents (Husen 2016), and the biomedical application of these compounds has exploited their anti-cancer (Chua et al. 2003), anti-malarial (Breidbach et al. 2002; Gysin et al. 1993), and anti-infectious (Wooldridge and Williams 1993) activities. Miller et al. (2011) reported that when conjugated with mycobactin analogs, the anti-malarial agent artemisinin exhibits activity against $M$. tuberculosis. Conjugates of siderophores and antibiotics are called "Trojan horse" antibiotics, in which the antibiotic compound utilizes the siderophores as a mediator for entry into cells via the ironuptake machinery (Möllmann et al. 2009; Ratledge and Dover 2000). Hence, the discovery of new siderophores with antibiotic properties provides valuable materials and insights that can drive drug discovery and development efforts.

In addition, we have performed computer-aided virtual screening on compounds in this study to look for potential viral development inhibitors (supplementary document). Lassa virus polymerase (PDB ID: 6KLC), Machupo virus polymerase (PDB ID: 6KLE), Influenza A virus polymerase (PDB ID: 6QX3), and Influenza D virus polymerase (PDB ID: 6KUJ) are key enzymes for virus replication. Notably, all the isolated compounds were docked onto the active site of 3'RNA pocket of virus polymerases to evaluate their binding affinities by using Gold program (Jones et al. 1997). Siderophores nocardimicins A-J (1-12) exhibited significant binding affinities with the four 3"'-RNA pockets of virus polymerases $(>90 \%)$ (Table S13). Virus infection severely 
affected healthy human beings (Peters et al. 1996); especially the emerging outbreak of COVID-2019 caused by SARSCoV-2 (Zhu et al. 2019) highlights the urgent need of developing broad-spectrum antivirus drugs. Our preliminary data revealed important potentials of these siderophores for broadspectrum antivirus drug development. Cell-based evaluation of virus polymerases inhibitory effects of these siderophores is ongoing.

This study expands the knowledge about the distribution and biodiversity of rare actinobacteria and their corresponding bioactive chemical entities from diverse environments in Xinjiang. Among the rare actinobacteria genera of our study, the genus Nocardia is the second most prevalent, and we show that Nocardia sp. XJ31 exerts anti-BCG activity by producing anthraquinone-type compounds. This study offers a strategy to investigate new bioactive compounds from microbes in extreme habitats.

Acknowledgments L. Zhang would like to thank the China Scholarship Council for the provision of China Government scholarship to support her Ph.D. study in the USA.

Author contributions XL and HD conceived and devised the project. Li Zhang, JZ, BR, WL, and CH participated in the experiments. JW, XM, $\mathrm{ML}$, and ZL isolated and identified the strains. RM and HD performed the bioactivity screen of these isolated compounds. JPL and KD performed the virtual screening for virus inhibitor. HD, XL, and LZ supervised the project. Li Zhang, JZ, and XL wrote the manuscript. All authors read and approved the manuscript.

Funding information This study was financially supported by the National Key Research and Development Program of China (2019YFA0906200), the National Natural Science Foundation of China (31720103901, 21877038, 21977029, 21877124, 81573341), Shanghai Rising-Star Program (20QA1402800), the Open Project Funding of the State Key Laboratory of Bioreactor Engineering, the 111 Project (B18022), Shanghai Science and Technology Commission (18JC1411900).

\section{Compliance with ethical standards}

This article does not contain any studies with human participants or animals performed by any of the authors.

Conflict of interest The authors declare that they have no conflicts of interest.

\section{References}

Ali SS, Vidhale N (2013) Bacterial siderophore and their application: a review. Int J Curr Microbiol App Sci 2(12):303-312

Andries K, Verhasselt P, Guillemont J, Göhlmann HW, Neefs J-M, Winkler H, Van Gestel J, Timmerman P, Zhu M, Lee E (2005) A diarylquinoline drug active on the ATP synthase of Mycobacterium tuberculosis. Science 307(5707):223-227. https://doi.org/10.1126/ science.1106753

Ashforth EJ, Fu C, Liu X, Dai H, Song F, Guo H, Zhang L (2010) Bioprospecting for antituberculosis leads from microbial metabolites. Nat Prod Rep 27(11):1709-1719. https://doi.org/10. 1039/c0np00008f

Bérdy J (2012) Thoughts and facts about antibiotics: where we are now and where we are heading. J Antibiot 65(8):385-395. https://doi. org/10.1038/ja.2012.27

Bloemberg GV, Keller PM, Stucki D, Trauner A, Borrell S, Latshang T, Coscolla M, Rothe T, Hömke R, Ritter C (2015) Acquired resistance to bedaquiline and delamanid in therapy for tuberculosis. N Engl J Med 373(20):1986-1988. https://doi.org/10.1056/NEJMc1505196

Breidbach T, Scory S, Krauth-Siegel RL, Steverding D (2002) Growth inhibition of bloodstream forms of Trypanosoma brucei by the iron chelator deferoxamine. Int J Parasitol 32(4):473-479. https://doi. org/10.1016/S0020-7519(01)00310-1

Butler MS, Buss AD (2006) Natural products - the future scaffolds for novel antibiotics? Biochem Pharmacol 71(7):919-929. https://doi. org/10.1016/j.bcp.2005.10.012

Camas M, Veyisoglu A, Sahin N (2014) Nocardia sungurluensis sp. nov., isolated from soil. Int J Syst Evol Microbiol 64(5):16291634. https://doi.org/10.1099/ijs.0.051334-0

Chaiharn M, Chunhaleuchanon S, Kozo A, Lumyong S (2008) Screening of rhizobacteria for their plant growth promoting activities. Cur Appl Sci Technol 8(1):18-23

Chua ACG, Ingram HA, Raymond KN, Baker E (2003) Multidentate pyridinones inhibit the metabolism of nontransferrin-bound iron by hepatocytes and hepatoma cells. Eur J Biochem 270(8):16891698. https://doi.org/10.1046/j.1432-1033.2003.03525.x

Cragg GM, Newman DJ (2013) Natural products: a continuing source of novel drug leads. Biochim Biophys Acta Gen Subj 1830(6):3670 3695. https://doi.org/10.1016/j.bbagen.2013.02.008

Dai HQ, Wang J, Xin YH, Pei G, Tang SK, Ren B, Ward A, Ruan J-S, Li WJ, Zhang LX (2010) Verrucosispora sediminis sp. nov., a cyclodipeptide-producing actinomycete from deep-sea sediment. Int J Syst Evol Microbiol 60(8):1807-1812. https://doi.org/10. 1099/ijs.0.017053-0

Dhakal D, Pokhrel AR, Shrestha B, Sohng JK (2017) Marine rare actinobacteria: Isolation, characterization, and strategies for harnessing bioactive compounds. Front Microbiol 8:1106. https:// doi.org/10.3389/fmicb.2017.01106

Dheda K, Gumbo T, Maartens G, Dooley KE, McNerney R, Murray M, Furin J, Nardell EA, London L, Lessem E (2017) The epidemiology, pathogenesis, transmission, diagnosis, and management of multidrug-resistant, extensively drug-resistant, and incurable tuberculosis. Lancet Respir Med 5(4):291-360. https://doi.org/10.1016/ S2213-2600(17)30079-6

Felsenstein J (1985) Confidence limits on phylogenies: an approach using the bootstrap. Evolution 39(4):783-791. https://doi.org/10.1111/j. 1558-5646.1985.tb00420.x

Gysin J, Crenn Y, da Silva LP, Breton C (1993) Siderophores as antiparasitic agents. Google Patents

Hayakawa M, Nonomura H (1987) Humic acid-vitamin agar, a new medium for the selective isolation of soil actinomycetes. J Ferment Technol 65(5):501-509. https://doi.org/10.1016/0385-6380(87) 90108-7

Huang P, Xie F, Ren B, Wang Q, Wang J, Wang Q, Abdel-Mageed WM, Liu M, Han J, Oyeleye A (2016) Anti-MRSA and anti-TB metabolites from marine-derived Verrucosispora sp. MS100047. Appl Microbiol Biotechnol 100(17):7437-7447. https://doi.org/10.1007/ s00253-016-7406-y

Husen E (2016) Screening of soil bacteria for plant growth promotion activities in vitro. Indonesian J AgrIC Sci 4(1):27-31. https://doi. org/10.21082/ijas.v4n1.2003.p27-31

Ikeda Y, Nonaka H, Furumai T, Onaka H, Igarashi Y (2005) Nocardimicins A, B, C, D, E, and F, siderophores with muscarinic M3 receptor inhibiting activity from Nocardia sp. TP-A0674. J Nat Prod 68(7):1061-1065. https://doi.org/10.1021/np050091j 
Jalal M, van der Helm D (1991) Isolation and spectroscopic identification of fungal siderophores. In: Handbook of microbial iron chelates. CRC Press, Boca Raton, pp 235-269

Jiang W, Zhong Y, Shen L, Wu X, Ye Y, Chen C-TA WB (2014) Stressdriven discovery of natural products from extreme marine environment-Kueishantao hydrothermal vent, a case study of metal switch valve. Curr Org Chem 18(7):925-934. https://doi.org/10. 2174/138527281807140515155705

Jones G, Willett P, Glen RC, Leach AR, Taylor R (1997) Development and validation of a genetic algorithm for flexible docking. J Mol Biol 267(3):727-748. https://doi.org/10.1006/jmbi.1996.0897

Katz L, Baltz RH (2016) Natural product discovery: past, present, and future. J Ind Microbiol Biotechnol 43(2-3):155-176. https://doi.org/ 10.1007/s10295-015-1723-5

Kieser T, Bibb M, Buttner M, Chater K, Hopwood D (2000) Growth and preservation of Streptomyces. Practical Streptomyces Genetics:4361

Küster E, Williams S (1964) Selection of media for isolation of Streptomycetes. Nature 202(4935):928-929. https://doi.org/10. $1038 / 202928 \mathrm{a} 0$

Lee CN, Heifets LB (1987) Determination of minimal inhibitory concentrations of antituberculosis drugs by radiometric and conventional methods. Am Rev Respir Dis 136(2):349-352. https://doi.org/10. 1164/ajrccm/136.2.349

Litwin CM, Calderwood S (1993) Role of iron in regulation of virulence genes. Clin Microbiol Rev 6(2):137-149. https://doi.org/10.1128/ CMR.6.2.137

Liu X, Chen C, He W, Huang P, Liu M, Wang Q, Guo H, Bolla K, Lu Y, Song F (2012) Exploring anti-TB leads from natural products library originated from marine microbes and medicinal plants. Anton Leeuw Int J G 102(3):447-461. https://doi.org/10.1007/s10482012-9777-0

Liu M, Abdel-Mageed WM, Ren B, He W, Huang P, Li X, Bolla K, Guo H, Chen C, Song F (2014a) Endophytic Streptomyces sp. Y3111 from traditional Chinese medicine produced antitubercular pluramycins. Appl Microbiol Biotechnol 98(3):1077-1085. https:// doi.org/10.1007/s00253-013-5335-6

Liu M, Zhang L, Ren B, Yang N, Yu X, Wang J, Ding L, Liu X, Liu Z, Goodfellow M (2014b) Prauserella shujinwangii sp. nov., from a desert environment. Int J Syst Evol Microbiol 64(11):3833-3837. https://doi.org/10.1099/ijs.0.065425-0

Liu M, Grkovic T, Zhang L, Liu X, Quinn RJ (2016) A model to predict anti-tuberculosis activity: value proposition for marine microorganisms. J Antibiot 69(8):594-599. https://doi.org/10.1038/ja.2016.87

Matsumoto M, Hashizume H, Tomishige T, Kawasaki M, Tsubouchi H, Sasaki H, Shimokawa Y, Komatsu M (2006) OPC-67683, a nitrodihydro-imidazooxazole derivative with promising action against tuberculosis in vitro and in mice. PLoS Med 3(11):e466. https:// doi.org/10.1371/journal.pmed.0030466

Meklat A, Sabaou N, Zitouni A, Mathieu F, Lebrihi A (2011) Isolation, taxonomy, and antagonistic properties of halophilic actinomycetes in Saharan soils of Algeria. Appl Environ Microbiol 77(18):6710 6714. https://doi.org/10.1128/AEM.00326-11

Mesfin YM, Hailemariam D, Biadglign S, Kibret KT (2014) Association between HIV/AIDS and multi-drug resistance tuberculosis: a systematic review and meta-analysis. PLoS One 9(1):e82235. https:// doi.org/10.1371/journal.pone.0082235

Miller MJ, Walz AJ, Zhu H, Wu C, Moraski G, Moellmann U, Tristani EM, Crumbliss AL, Ferdig MT, Checkley L, Edwards RL, Boshoff Helena I (2011) Design, synthesis, and study of a mycobactinartemisinin conjugate that has selective and potent activity against tuberculosis and malaria. J Am Chem Soc 133(7):2076-2079. https://doi.org/10.1021/ja109665t

Möllmann U, Heinisch L, Bauernfeind A, Köhler T, Ankel-Fuchs D (2009) Siderophores as drug delivery agents: application of the
"Trojan Horse" strategy. Biometals 22(4):615-624. https://doi.org/ 10.1007/s10534-009-9219-2

Mukai A, Fukai T, Hoshino Y, Yazawa K, Harada K-i, Mikami Y (2009) Nocardithiocin, a novel thiopeptide antibiotic, produced by pathogenic Nocardia pseudobrasiliensis IFM 0757. J Antibiot 62(11): 613-619. https://doi.org/10.1038/ja.2009.90

Newman DJ, Cragg GM (2016) Natural products as sources of new drugs from 1981 to 2014. J Nat Prod 79(3):629-661. https://doi.org/10. 1021/acs.jnatprod.5b01055

Nonomura H (1969) Distribution of actinomycetes in soil.(VI) A culture method effective for both preferential isolation and enumeration of Microbispora and Streptosporangium in soil (Part I). J Ferment Technol 47:463-469

Okoro CK, Brown R, Jones AL, Andrews BA, Asenjo JA, Goodfellow M, Bull AT (2009) Diversity of culturable actinomycetes in hyperarid soils of the Atacama Desert, Chile. Anton Leeuw Int J G 95(2): 121-133. https://doi.org/10.1007/s10482-008-9295-2

Peters CJ, Jahrling PB, Khan AS (1996) Patients infected with highhazard viruses: scientific basis for infection control. In: Schwarz TF, Siegl G (eds) Imported virus infections. Archives of Virology Supplement II, vol 11. Springer, Vienna. https://doi.org/10.1007/ 978-3-7091-7482-1_13

Pettit RK (2011) Culturability and secondary metabolite diversity of extreme microbes: expanding contribution of deep sea and deep-sea vent microbes to natural product discovery. Mar Biotechnol 13(1): 1-11. https://doi.org/10.1007/s10126-010-9294-y

Ratledge C, Dover LG (2000) Iron metabolism in pathogenic bacteria. Annu Rev Microbiol 54(1):881-941. https://doi.org/10.1146/ annurev.micro.54.1.881

Ruggiero C, Neu M, Matonic J, Reilly S (2000) Interactions of Pu with desferrioxamine siderophores can affect bioavailability and mobility. Actinide Res Q 2000:16-18

Saha R, Saha N, Donofrio RS, Bestervelt LL (2013) Microbial siderophores: a mini review. J Basic Microbiol 53(4):303-317. https://doi.org/10.1002/jobm.201100552

Saitou N, Nei M (1987) The neighbor-joining method: a new method for reconstructing phylogenetic trees. Mol Biol Evol 4(4):406-425. https://doi.org/10.3390/molecules23061371

Seyedsayamdost MR, Traxler MF, Zheng S-L, Kolter R, Clardy J (2011) Structure and biosynthesis of amychelin, an unusual mixed-ligand siderophore from Amycolatopsis sp. AA4. J Am Chem Soc 133(30): 11434-11437. https://doi.org/10.1021/ja203577e

Shirling ET, Gottlieb D (1966) Methods for characterization of Streptomyces species. Int J Syst Bacteriol 16(3):313-340. https:// doi.org/10.1099/00207713-16-3-313

Subramani R, Aalbersberg W (2013) Culturable rare actinomycetes: diversity, isolation and marine natural product discovery. Appl Microbiol Biotechnol 97(21):9291-9321. https://doi.org/10.1007/ s00253-013-5229-7

Subramani R, Sipkema D (2019) Marine rare actinomycetes: a promising source of structurally diverse and unique novel natural products. Mar Drugs 17(5):249. https://doi.org/10.3390/md17050249

Tamura K, Peterson D, Peterson N, Stecher G, Nei M, Kumar S (2011) MEGA5: molecular evolutionary genetics analysis using maximum likelihood, evolutionary distance, and maximum parsimony methods. Mol Biol Evol 28(10):2731-2739. https://doi.org/10. 1093/molbev/msr121

Tan GYA, Ward AC, Goodfellow M (2006) Exploration of Amycolatopsis diversity in soil using genus-specific primers and novel selective media. Syst Appl Microbiol 29(7):557-569. https:// doi.org/10.1016/j.syapm.2006.01.007

Thompson JD, Higgins DG, Gibson TJ (1994) CLUSTAL W: improving the sensitivity of progressive multiple sequence alignment through sequence weighting, position-specific gap penalties and weight matrix choice. Nucleic Acids Res 22(22):4673-4680. https://doi.org/ $10.1093 / \mathrm{nar} / 22.22 .4673$ 
Tsuda M, Sato H, Tanaka Y, Yazawa K, Mikami Y, Sasaki T, Kobayashi J (1996) Brasiliquinones A-C, new cytotoxic benz[a]anthraquinones with an ethyl group at C-3 from actinomycete Nocardia brasiliensis. J Chem Soc Perkin Trans 1:1773-1775. https://doi.org/10.1039/P19960001773

Tsuda M, Nemoto A, Komaki H, Tanaka Y, Yazawa K, Mikami Y, Ji K (1999) Nocarasins A-C and brasiliquinone D, new metabolites from the actinomycete Nocardia brasiliensis. J Nat Prod 62(12):16401642. https://doi.org/10.1021/np990265v

Wang JF, Dai HQ, Wei YL, Zhu HJ, Yan YM, Wang YH, Long CL, Zhong HM, Zhang LX, Cheng YX (2010a) Antituberculosis agents and an inhibitor of the para-aminobenzoic acid biosynthetic pathway from hydnocarpus anthelminthica seeds. Chem Biodivers 7(8): 2046-2053. https://doi.org/10.1002/cbdv.201000072

Wang J, Li Y, Bian J, Tang SK, Ren B, Chen M, Li WJ, Zhang LX (2010b) Prauserella marina sp. nov., isolated from ocean sediment of the South China Sea. Int J Syst Evol Microbiol 60(4):985-989. https://doi.org/10.1099/ijs.0.013862-0

Wang Q, Song F, Xiao X, Huang P, Li L, Monte A, Abdel-Mageed WM, Wang J, Guo H, He W (2013) Abyssomicins from the South China
Sea deep-sea sediment Verrucosispora sp.: natural thioether michael addition adducts as antitubercular prodrugs. Angew Chem Int Ed 52(4):1231-1234. https://doi.org/10.1002/anie.201208801

Wayne P (2002) National committee for clinical laboratory standards. Performance standards for antimicrobial disc susceptibility testing 28th ed. CLSI supplement M100

WHO Global Tuberculosis Report (2018) https://www.who.int/tb/ publications/global_report/en/. Accessed 26 September 2018.

Wooldridge KG, Williams PH (1993) Iron uptake mechanisms of pathogenic bacteria. FEMS Microbiol Rev 12(4):325-348. https://doi. org/10.1111/j.1574-6976.1993.tb00026.x

Zhu N, Zhang DY, Wang WL, Li XW, Yang B, Song JD, Zhao X, Huang BY, Shi WF, Lu RJ, Niu PH, Zhan FX, Ma XJ, Wang DY, Xu WB, Wu GZ, Gao GF, Tan WJ (2019) A novel coronavirus from patients with pneumonia in china, 2019. N Engl J Med 382:727-733. https:// doi.org/10.1056/NEJMoa2001017

Publisher's note Springer Nature remains neutral with regard to jurisdictional claims in published maps and institutional affiliations. 